\title{
COULD THYROID REPLACEMENT THERAPY NOT BE ENOUGH TO REDUCE OXIDATIVE STRESS IN HYPOTHYROID PATIENTS WITH DOWN' SYNDROME? A COHORT STUDY.
}

E.R. Villani ${ }^{1}$, A. Carfi ${ }^{1}$, C. Di Segni ${ }^{2}$, S. Raimondo ${ }^{2}$, G. Onder ${ }^{1}$, A. Mancini $^{2}$
1. Department of Geriatrics, "Centro Medicina dell'Invecchiamento", Catholic University of the Sacred Heart, Rome, Italy
2. Department of Medical Sciences, Division of Endocrinology, Catholic University of the Sacred Heart, Rome, Italy

\section{Objective}

Hypothyroidism and autoimmune thyroiditis are prevalent in patients with Down' syndrome (DS), leading to wide prescription of thyroid replacement therapy. On the other hand, thyroid function is involved in oxidative stress (OS) mechanisms. DS is a well-known high os condition because several genes involved in OS mechanisms map on chromosome 21 and Coenzyme Q10, lipophilic antioxidant, could be more correlated with hypothyroidism than TSH in DS people.

To investigate relationships among thyroid function, OS and replacement therapy, we enrolled 26 adults with DS (10 males) aged 18-64. Fourteen of them were under thyroid replacement therapy with levotiroxine.

\section{Methods}

A fasting blood plasma sample was collected at 9:00 am and TSH (n.r. 0.30-2,80 uUI/I), fT4 levels and total antioxidant capacity (TAC) were evaluated.

TAC was assayed by a method based on the interaction between $\mathrm{H}_{2} \mathrm{O}_{2}$-metamyoglobin, as source of radicals, and the chromogenous ABTS, whose radical cation is spectroscopically revealed. The latency time (LAG, sec) in ABTS'+ appearance is proportional to antioxidant concentration.

Patients were classified in two groups:

a) patients undergoing thyroid replacement therapy $(14 / 26)$ and b) patients without replacement therapy $(12 / 26)$.

\begin{tabular}{l}
\hline Results \\
Among the first group, only $57 \%$ \\
$(8 / 14)$ of patients were euthyroid \\
(mean \pm SD TSH $=3.01 \pm 3.27$ \\
uUl/mL). Only $58 \%(7 / 12)$ was \\
euthyroid in the second group \\
(mean \pm SD TSH $2.39 \pm 1.09$ \\
uUl/mL). \\
TAC was lower in the first \\
group (62.50 \pm 14.64 sec) \\
rather than in the second \\
group (74.17 $\pm \mathbf{1 2 . 4 0 ~ s e c ) ,}$ \\
regardless of TSH level.
\end{tabular}
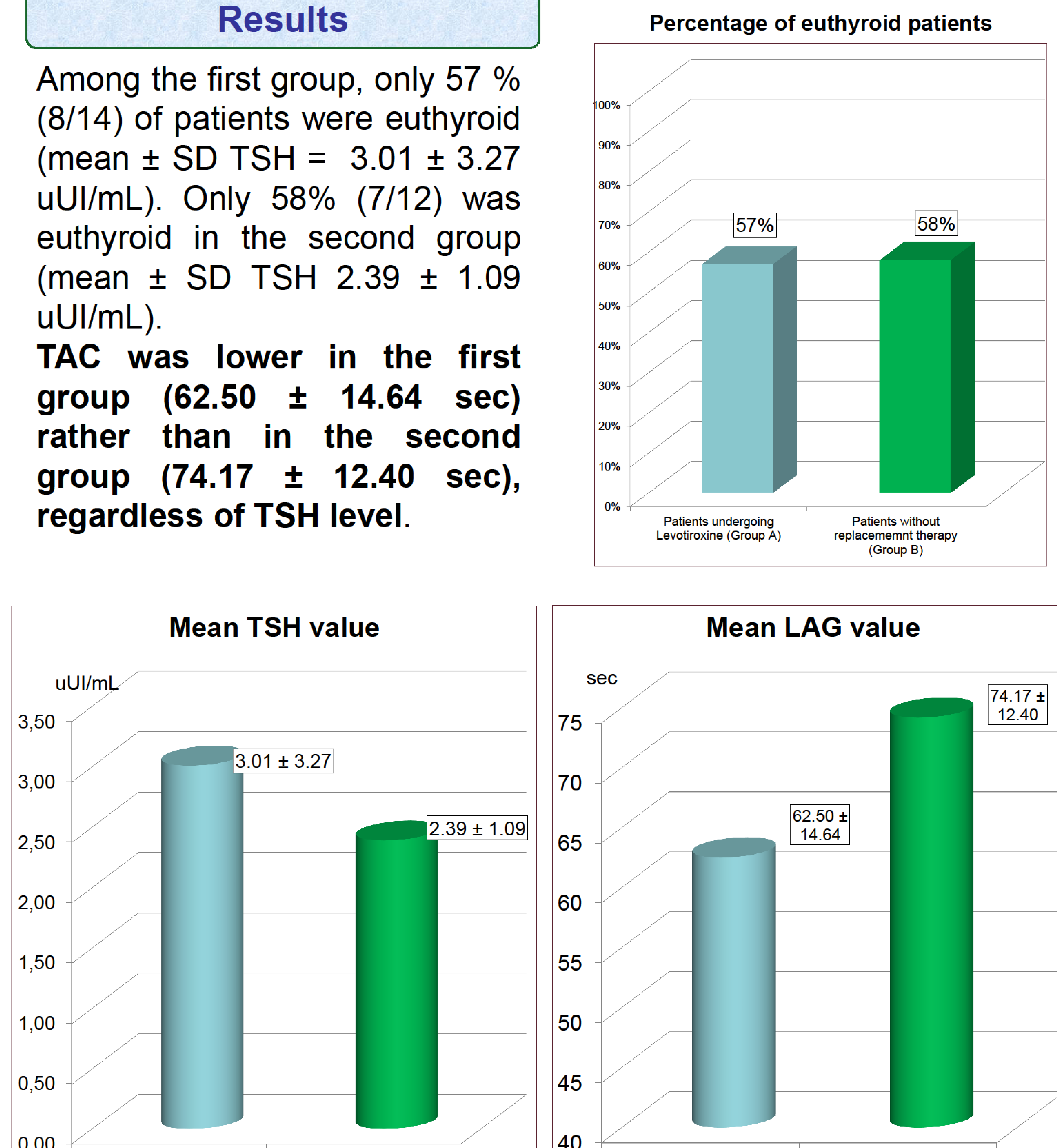

Group A Group B

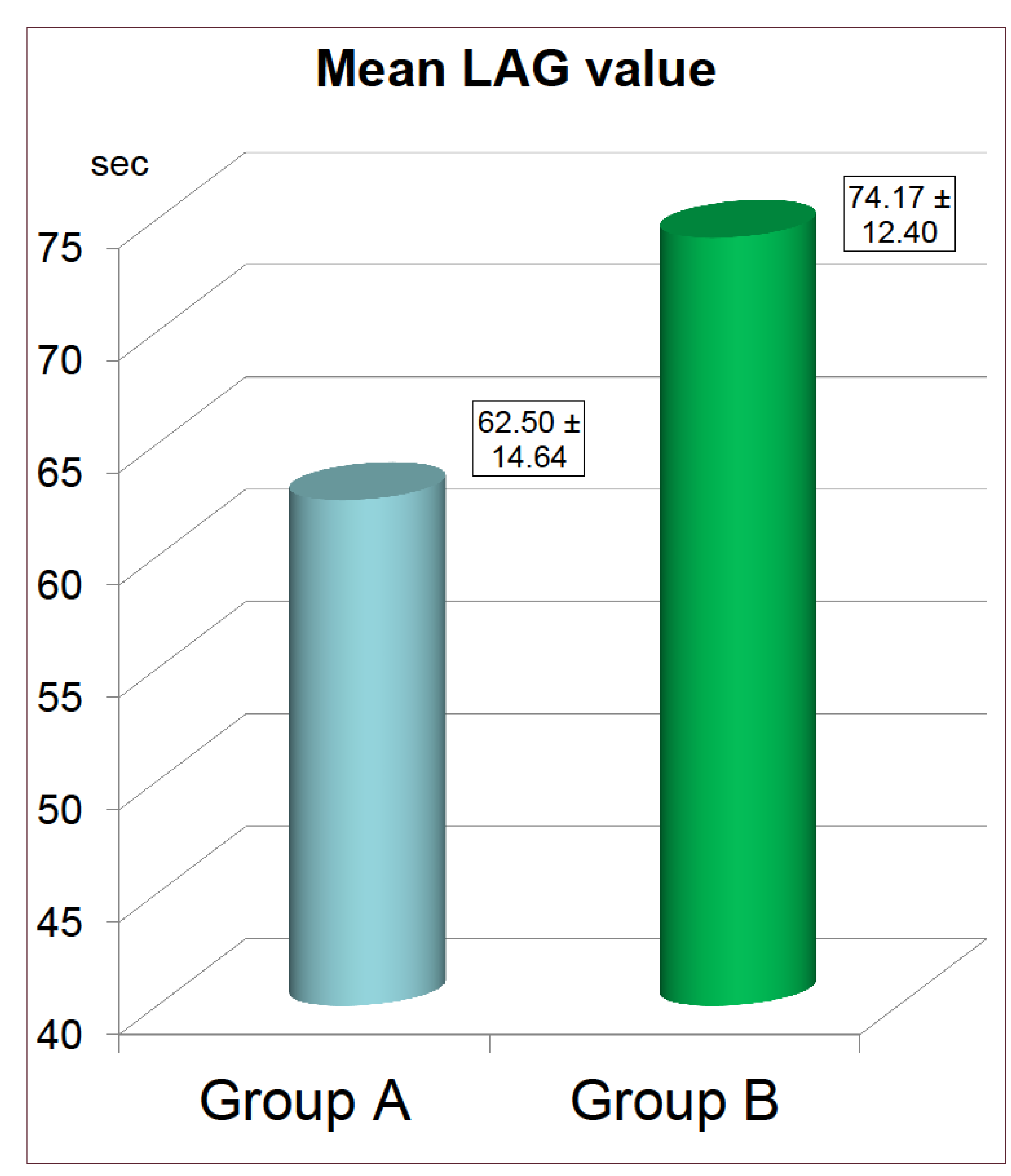

\section{Conclusions}

These data underline the role of hypothyroidism as a high OS condition and suggest that replacement therapy alone could not be enough to establish normal TAC levels in hypothyroid patients.

Further studies will be necessary to evaluate whether a supplementation with antioxidants should be considered in DS hypothyroid patients, due to the compresence of two causes of high oxidative stress in those patients. It could also be necessary to evaluate whether non-DS hypothyroid patients under thyroid replacement therapy show higher OS levels. 